PINTO, L.C.F. et al. Efeito dos níveis de proteína bruta da ração no comportamento e maturidade sexual de suínos machos. PUBVET, Londrina, V. 5, N. 20, Ed. 167, Art. 1128, 2011.

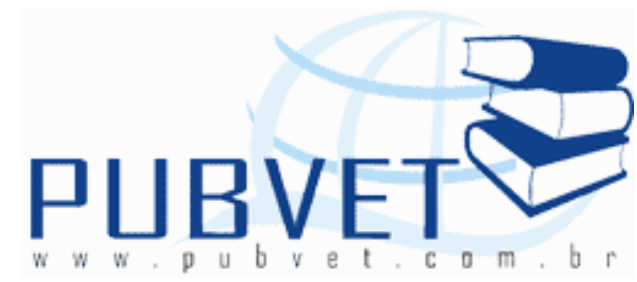

PUBVET, Publicações em Medicina Veterinária e Zootecnia.

\title{
Efeito dos níveis de proteína bruta da ração no comportamento e maturidade sexual de suínos machos ${ }^{1}$
}

Luiz Claúdio Ferreira Pinto²; Karen Martins Leão ${ }^{3}$; Natália do Carmo Silva²; Liomar de Sousa Araújo²; Rossane Pereira da Silva²; Marco Antônio Pereira da Silva ${ }^{4}$

${ }^{1}$ Trabalho apresentado pelo primeiro autor como parte das exigências para conclusão do curso de bacharelado de Zootecnia do Instituto Federal de Educação, Ciência e Tecnologia Goiano - Campus Rio Verde;

'Zootecnista pelo Instituto Federal de Educação, Ciência e Tecnologia Goiano Campus Rio Verde;

${ }^{3}$ Médica Veterinária, Profa. Dra. do Instituto Federal de Educação, Ciência e Tecnologia Goiano - Campus Rio Verde;

${ }^{4}$ Zootecnista, Prof. Dr. do Instituto Federal de Educação, Ciência e Tecnologia Goiano - Campus Rio Verde, e-mail: marcotonyrv@yahoo.com.br

\section{Resumo}

O objetivo do trabalho foi avaliar o efeito do arraçoamento com diferentes níveis de proteína bruta sob a maturidade sexual e qualidade de sêmen de cachaços. Os suínos foram alimentados com rações contendo 12\%, 16\% e $20 \%$ de proteína bruta. Foram utilizados 11 animais de linhagens comerciais. Para avaliação do comportamento sexual e adaptação dos leitões, a partir de 
PINTO, L.C.F. et al. Efeito dos níveis de proteína bruta da ração no comportamento e maturidade sexual de suínos machos. PUBVET, Londrina, V. 5, N. 20, Ed. 167, Art. 1128, 2011.

151 dias de idade os animais eram colocados em contato com o manequim para colheita de sêmen uma vez por semana, por 15 minutos. Avaliou-se concentração (milhões $/ \mathrm{mL}$ ), Motilidade Total (MT), Motilidade Progressiva (MP), Vigor (V) e alterações morfológicas (AM). Os animais alimentados com rações contendo $16 \%$ de PB apresentaram melhores resultados de comportamento macho. Os resultados médios dos parâmetros: saltos sobre o manequim, número de montas, exposição de pênis, MT, MP, V e concentração espermática, não diferiram entre os tratamentos a $5 \%$ de significância. Os valores de $A M$ encontradas neste estudo diferiram estatisticamente entre si. $O$ parâmetro maturidade sexual apresentou diferença significativa entre os suínos que receberam ração contendo $20 \%$ e os animais que receberam rações com $12 \%$ e $16 \%$ de $\mathrm{PB}$. Os suínos machos não castrados do $\mathrm{T} 16 \%$ apresentaram melhor comportamento macho. Não houve diferença na qualidade do sêmen de varrões arraçoados com diferentes níveis de proteína bruta $(12,16$ e $20 \%)$ desde a desmama até atingirem a maturidade sexual. Os animais que receberam ração com $20 \%$ de PB atingiram a maturidade sexual mais precocemente.

Palavras-chave: suinocultura; qualidade do sêmen; teor protéico; puberdade.

\title{
Effect of the rude protein levels of the diet in the behavior and sexual maturity of male swines
}

\begin{abstract}
The objective of the work was evaluate the effect of the feeding with different rude protein levels under the sexual maturity and quality of semen of boars. The swines were fed with diets contend $12 \%, 16 \%$ and $20 \%$ of rude protein. Were used 11 animals of commercial ancestries. For evaluation of the sexual behavior and adaptation of the piglets, from 151 days of age the animals were placed in contact with the dummy for semen harvest one time per week, per
\end{abstract}


PINTO, L.C.F. et al. Efeito dos níveis de proteína bruta da ração no comportamento e maturidade sexual de suínos machos. PUBVET, Londrina, V. 5, N. 20, Ed. 167, Art. 1128, 2011.

15 minutes. Evaluated concentration (millions $/ \mathrm{mL}$ ), total motility (TM), progressive motility (MP), vigor ( $v$ ) and morphologic alterations (AM). The animals fed with diets contend $16 \%$ of PB presented better resulted of male behavior. The average results of the parameters: jumps on the dummy, number of mount, exposition of penis, TM, MP, V and spermatic concentration, not differed between the treatments $5 \%$ from significance. The values of $A M$ found in this study differed statistical between itself. The parameter sexual maturity presented significant difference between the swines that received diets contend $20 \%$ and the animals that received diets with $12 \%$ and $16 \%$ from $\mathrm{PB}$. The castrated male swines of $\mathrm{T} 16 \%$ not presented male behavior better. Not have difference in the quality of the semen of boars feeding with different rude protein levels $(12 \%, 16 \%$ and $20 \%$ ) since weans until reaching the sexual maturity. The animals that received diets with $20 \%$ from PB reached the sexual maturity more precociously.

Keywords: swine; quality of the semen; protein; puberty.

\section{INTRODUÇÃO}

O avanço do setor suinícola brasileiro permitiu que se desenvolvessem por meio de programas de manejo, melhoramento e nutrição, animais cada vez mais produtivos. No entanto, uma categoria animal vem sendo de certa forma negligenciada, como é o caso dos varrões e cachaços. Esses animais recebem pouca atenção quanto a nutrição, isso pode se dar pelo fato de se encontrarem em menor número na granja, o que os limita a serem arraçoados com as mesmas rações que as matrizes em gestação, e em alguns casos até a mesma ração que os animais destinados ao abate. Este é um problema que cada vez mais, vem sendo observado por profissionais em nutrição nas propriedades suinícolas.

Os reprodutores são responsáveis por $50 \%$ do material genético da granja suinícola, além da importância em produzir estímulos táteis, olfatórios, 
PINTO, L.C.F. et al. Efeito dos níveis de proteína bruta da ração no comportamento e maturidade sexual de suínos machos. PUBVET, Londrina, V. 5, N. 20, Ed. 167, Art. 1128, 2011.

auditivos e visuais nas fêmeas. FLOWERS, (1998) relatou que enquanto a produção anual de uma matriz gira em torno de 25 animais, um único reprodutor pode gerar de 6000 a 7000 descendentes por ano, desde que seja utilizado o regime de colheita de sêmen para inseminação artificial (IA). Os machos destinados a reprodução devem receber tratamentos diferenciados das demais categorias, pois o manejo nutricional inadequado pode resultar em prejuízos reprodutivos, produtivos, e prejudicar o crescimento do animal, retardando assim a maturidade sexual.

O manejo nutricional adequado dos suínos machos destinados a reprodução resulta em melhoria da capacidade reprodutiva e utilização desses animais por mais tempo no plantel. O desempenho reprodutivo dos cachaços pode ser descrito pela avaliação de três características principais: libido, número de células espermáticas produzidas por unidade de tempo e capacidade fertilizante das mesmas (VALENÇA et al., 2007). Estas características podem sofrer a influência de vários fatores biológicos, que podem ser representados pelo potencial genético, tamanho de testículo, libido e idade do animal (KEMP \& VERSTEGEN, 1991).

As relações entre níveis nutricionais e eficiência reprodutiva, têm sido avaliadas com base nos parâmetros de biometria testicular, comportamento sexual, produção e qualidade do sêmen (KEMP \& VERSTEGEN, 1991). As variações no consumo de alimentos, eficiência alimentar e qualidade de carcaça dos suínos, evidenciam a necessidade de que sejam definidas as exigências nutricionais para as diferentes categorias e fases do desenvolvimento fisiológico dos animais (SILVA et al., 1998). A alimentação é um importante fator no desenvolvimento dos animais, sendo necessário que estes recebam alimentação adequada desde o desmame até o início da vida reprodutiva. Dessa forma, estarão assegurados os processos de maturação fisiológica, bioquímica e comportamental que se desenrolam até a puberdade, o que refletirá em um encaminhamento normal da espermatogênese, na expressão da libido e na qualidade e quantidade do ejaculado obtido (BROWN, 
PINTO, L.C.F. et al. Efeito dos níveis de proteína bruta da ração no comportamento e maturidade sexual de suínos machos. PUBVET, Londrina, V. 5, N. 20, Ed. 167, Art. 1128, 2011.

1994).

Problemas de subnutrição em animais na fase pré-púbere, geralmente resultam em retardo no desenvolvimento sexual, atraso na chegada a puberdade, demora no desenvolvimento da genitália externa e consequente supressão da espermatogênese (LEATHEM, 1970). Deficiências energéticas e protéicas em rações fornecidas a leitões destinados a servirem como reprodutores, durante um período de 40 a 50 dias após o desmame (21dias), resultaram em danos nas células intersticiais (células de Leydig), as quais apresentaram uma redução do citoplasma bastante evidente, demonstrando redução de diâmetro em até dois terços do observado em células normais (PLATT \& STEWART, 1967). Ainda segundo esses pesquisadores os efeitos perduraram por todo o período reprodutivo destes animais. Sendo assim, a correta alimentação é essencial para a obtenção de um bom desempenho (DONZELE et al., 1994).

Muitos animais não são capazes de obter uma ejaculação voluntária antes dos seis meses de vida, devido à existência de uma série de fatores que poderão influenciar no desenvolvimento sexual como, a nutrição, o ambiente em que são criados e os fatores genéticos (FLOWERS, 1996).

Um bom reprodutor deve demonstrar boa libido, boa capacidade de realizar a monta e produção adequada de espermatozóides férteis. Para que se consiga alcançar estes índices, devem ser adotadas práticas de manejo com o reprodutor desde sua fase pré-púbere, pois as falhas ocorridas neste período como a má nutrição, podem acarretar problemas reprodutivos futuros, como o desenvolvimento testicular inadequado (COLENBRANDER \& KEMP, 1990).

O objetivo do presente trabalho foi avaliar o efeito do arraçoamento com diferentes níveis de proteína bruta sob o comportamento, a maturidade sexual e a qualidade de sêmen de cachaços. 
PINTO, L.C.F. et al. Efeito dos níveis de proteína bruta da ração no comportamento e maturidade sexual de suínos machos. PUBVET, Londrina, V. 5, N. 20, Ed. 167, Art. 1128, 2011.

\section{REVISÃO DE LITERATURA}

\subsection{Situação da Suinocultura no Brasil e no Mundo}

Segundo a Associação Brasileira da Indústria Produtora e Exportadora de Carne Suína e Empresa Brasileira de Pesquisa Agropecuária (ABIPECS/Embrapa, 2010) o Brasil produziu estimativamente em 2009 ao redor de 3.190,4 mil de toneladas de carne suína e exportou em abril de 2010, 51.251 mil toneladas, e estima-se ainda que a quantidade de matrizes alojadas no Brasil neste período será de 2.432.281 milhões de cabeças. Ainda segundo a mesma fonte, o estado de Goiás possuía em 2008, 68 mil matrizes alojadas com um total de leitões 22,8 terminados/matriz/ano, sendo este valor o mais alto dentre os demais estados neste ano. De acordo com IBGE (2009) os principais países compradores do produto brasileiro são a Rússia, Hong Kong, Angola, Ucrânia, Argentina e Cingapura.

De acordo com GONÇALVES \& PALMEIRA (2006) o Brasil possuía nesse ano o terceiro maior rebanho mundial de suínos com mais de 32 milhões de cabeças, sendo superado apenas pelos Estados Unidos, com um rebanho superior a 60 milhões de animais, e pela China com o maior rebanho de suínos, com mais de 460 milhões de animais. Segundo o mesmo autor o crescimento do rebanho de suínos no Brasil tem se mantido praticamente constante, enquanto que o número de matrizes suínas decresceu nos últimos dez anos.

No Brasil estima-se a realização de 1,6 milhão de inseminações artificiais, o que equivale à utilização desta técnica em $51 \%$ das matrizes do plantel tecnificado, na última década, houve um aumento de $1.700 \%$ no emprego da inseminação artificial IA na suinocultura brasileira (OBERLENDER et al., 2008). O principal fator responsável pelo progresso genético da espécie suína foi á necessidade de atender as exigências do mercado consumidor no que diz respeito à qualidade da carne e teor de gordura na carcaça (BORTOLOZZO et al., 2005a). De acordo com ROPPA (2002) estima-se que 
PINTO, L.C.F. et al. Efeito dos níveis de proteína bruta da ração no comportamento e maturidade sexual de suínos machos. PUBVET, Londrina, V. 5, N. 20, Ed. 167, Art. 1128, 2011.

mais de 730 mil pessoas dependem diretamente da suinocultura, sendo essa atividade responsável pela renda de mais de 2,7 milhões de pessoas.

\subsection{Maturidade Sexual de Suínos}

A correta utilização dos machos do plantel compreende a realização do número de coletas semanais adequado à idade dos animais (BORTOLOZZO et al., 2005). É recomendada a coleta de sêmen de machos com idade entre 7 a 12 meses uma vez por semana, 12 a 15 meses 3 vezes em 2 semanas e, a partir dessa idade, altera-se o protocolo para duas vezes por semana (WOLLMANN et al., 2002). A norma que orienta o manejo de machos jovens preconiza a entrada em serviço em torno dos oito meses de idade (SCHEID \& AFONSO, 2000). A entrada em serviço dos reprodutores jovens é determinada basicamente em função dos aspectos associados aos processos de puberdade, maturidade sexual, desempenho sexual e reprodutivo (OBERLENDER et al., 2010). Como os padrões de comportamento sexual se desenvolvem durante a fase de crescimento (NEELY, 1982), o contato físico com outros animais nessa fase é fundamental para a expressão da libido em machos jovens (SCHEID \& AFONSO, 2000).

A idade a puberdade é um parâmetro controverso, haja vista as diferentes definições para esse termo, sendo que do ponto de vista prático, um animal atinge a puberdade quando for capaz de liberar gametas e manifestar uma seqüência completa do comportamento sexual (PRADO, 2002).

A maturidade sexual se dá na fase pós-puberal, quando os testículos ainda se encontram em desenvolvimento e a espermatogênese se assemelha à do animal adulto (FERREIRA, 1995). Suínos encontram-se aptos à reprodução por ocasião da puberdade, porém a maturidade sexual só ocorre um pouco mais tarde, quando o sêmen produzido já estará dentro dos padrões normais para suínos (MURGAS et al., 2001). De acordo com SILVA et al. (2008), nos machos $O$ ato de fungar, salivar, e focinhar as fêmeas são os padrões mais freqüentes. FERREIRA et al. (2005) obtiveram resultados que sugeriram que a 
PINTO, L.C.F. et al. Efeito dos níveis de proteína bruta da ração no comportamento e maturidade sexual de suínos machos. PUBVET, Londrina, V. 5, N. 20, Ed. 167, Art. 1128, 2011.

libido e a capacidade de monta não são fatores limitantes para o início da vida reprodutiva em machos suínos Landrace (LD) e Large White (LW).

Segundo FERREIRA et al. (2005), a utilização do reprodutor suíno baseia-se em sua habilidade de montar no manequim, libido, características sexuais e reprodutivas desejáveis e principalmente pela produção de um ejaculado capaz de determinar boas taxas de fertilização. A qualidade do sêmen em animais púberes é relativamente baixa, quando comparada com a de animais adultos (MURGAS et al., 2001). O volume e a concentração aumentam gradativamente no período pós-puberal, acompanhados de um aumento no número de espermatozóides vivos e morfologicamente normais e, conseqüentemente, na motilidade, levando a um aumento no potencial fertilizante do sêmen (MORROW, 1986).

Um atributo importante para o deslocamento espermático no trato reprodutivo e para a penetração no oócito é a motilidade, por ser um exame simples, rápido, de baixo custo e um bom indicador da integridade e funcionalidade das membranas (GADEA, 2005), a avaliação subjetiva da motilidade espermática é o principal parâmetro utilizado para selecionar os ejaculados (BERNARDI, 2008).

O exame de morfologia espermática é uma ferramenta fundamental para o descarte do ejaculado e até mesmo do reprodutor (BORTOLOZZO et al., 2005b). De acordo com FURTADO et al. (2006), o exame de morfologia espermática faz parte da avaliação qualitativa do ejaculado e permite a determinação da freqüência de cada uma das anormalidades espermáticas e do percentual total de alterações na amostra de sêmen, e esse parâmetro é utilizado como indicativo do potencial fecundante do ejaculado, pois as alterações interferem na capacidade de movimentação e fecundação do espermatozóide, de acordo com a localização do defeito. No manual para exame andrológico e avaliação de sêmen animal descrito pelo Colégio Brasileiro de Reprodução Animal (CBRA, 1998) as alterações morfológicas totais devem ser inferiores a $20 \%$. É considerado sêmen normal aquele com 
PINTO, L.C.F. et al. Efeito dos níveis de proteína bruta da ração no comportamento e maturidade sexual de suínos machos. PUBVET, Londrina, V. 5, N. 20, Ed. 167, Art. 1128, 2011.

número de células espermáticas morfologicamente anormais dentro dos limites aceitáveis (FURTADO et al., 2006).

FEITSMA et al., (2006) observaram que em ejaculados com média de $15,5 \%$ de defeitos, foi calculada uma diminuição de $0,2 \%$ na taxa de não retorno ao estro, de 0,5\% na taxa de parto, e de 0,08 leitões nascidos para um aumento de $20 \%$ a $30 \%$ no percentual de anormalidades. É importante salientar que, mesmo quando os parâmetros morfológicos encontram-se dentro dos limites aceitáveis, o resultado do exame não permite estabelecer o nível de real fertilidade do ejaculado (MARTÍNEZ \& ERIKSSON, 2000). Avaliar o potencial fertilizante de um ejaculado geralmente inclui testes de função espermática, bem como a avaliação da morfologia espermática, os perfis de motilidade, concentração e viabilidade (TARDIF et al., 1999). O impacto econômico de diferenciar a fertilidade de machos advém do fato de eliminar ou limitar o uso de machos menos férteis (BERNARDI, 2008).

\subsection{Efeitos da Nutrição na Qualidade do Sêmen de Suínos}

A alimentação adequada dos animais destinados à reprodução deve ser realizada desde o momento do desmame e perdurar durante todo o seu desenvolvimento VALENÇA et al., (2007), pois de acordo com BROWN (1994), estarão assegurados os processos de maturação fisiológica, bioquímica e comportamental que se desenrolam até a puberdade, o que refletirá em um encaminhamento normal da espermatogênese, na expressão da libido e na qualidade e quantidade do ejaculado obtido.

As exigências de proteína e aminoácidos para reprodutores em crescimento ainda não foram bem determinadas (PRADO, 2002). Problemas de subnutrição em animais na fase pré-púbere, geralmente resultaram em retardo no desenvolvimento sexual, atraso na chegada à puberdade, demora no desenvolvimento da genitália externa e consequente supressão da espermatogênese (LEATHEM, 1970).

Atualmente, não existe recomendação adequada de exigência nutricional 
PINTO, L.C.F. et al. Efeito dos níveis de proteína bruta da ração no comportamento e maturidade sexual de suínos machos. PUBVET, Londrina, V. 5, N. 20, Ed. 167, Art. 1128, 2011.

para machos reprodutores em crescimento, nas tabelas de exigências nutricionais brasileiras (ROSTAGNO, 2000). Porém, é importante fornecer uma ração que esteja em perfeito equilíbrio de nutrientes (OBERLENDER et al., 2008).

Animais jovens são mais sensíveis a problemas relacionados com má nutrição do que aqueles já adultos e, em algumas circunstâncias, podem sofrer danos que podem repercutir em toda sua vida reprodutiva (FERRELL,1991).

A nutrição dos reprodutores mostra-se de forma contraditória, uma vez que na fase de crescimento, tem recebido a mesma ração de fêmeas e castrados, porém machos não castrados crescem mais rápido que as fêmeas e castrados, necessitando de ração com maior porcentagem de proteína, dessa forma, deve-se considerar uma nutrição que permita o crescimento adequado do animal (PRADO, 2002).

No estudo realizado por VALENÇA (2004), onde foram utilizadas dietas contendo diferentes níveis protéicos, nas diferentes fases de desenvolvimento reprodutivo em reprodutores suínos dos 38 aos 210 dias de idade, a manutenção do processo espermatogênico, ocorreu de forma equilibrada entre os diferentes grupos experimentais.

KEMP et al., (1989) concluíram que a variação na ingestão de proteína por varrões já maduros não exercia grandes efeitos sobre a qualidade e a quantidade de sêmen produzido, exceto quando do fornecimento de uma alimentação pobre neste nutriente por um período de tempo prolongado. YEN \& YU (1985), não encontraram efeitos significativos sobre a porcentagem de espermatozóides defeituosos através da elevação dos níveis protéicos na dieta.

De acordo com a composição de cada dieta, podem ser encontradas alterações no volume de ejaculado obtido e na atividade dos andrógenos sem, necessariamente, afetar a espermatogênese, sugerindo que certos constituintes podem afetar diferentemente a produção e/ou a liberação dos hormônios luteinizante e folículo estimulante (BROWN, 1994).

A redução dos níveis protéicos tende, geralmente, a ocasionar diminuição 
PINTO, L.C.F. et al. Efeito dos níveis de proteína bruta da ração no comportamento e maturidade sexual de suínos machos. PUBVET, Londrina, V. 5, N. 20, Ed. 167, Art. 1128, 2011.

na secreção de fluidos seminais e na qualidade do sêmen obtido (VALENÇA et al., 2007). Porém, os efeitos endócrinos e fisiológicos negativos podem ser apenas temporários, quando observados em reprodutores já maduros, pois, o fornecimento de dietas com níveis energéticos e protéicos normalizados podem reverter estes problemas (BROWN, 1994).

LOUIS et al. (1994), não encontraram diferenças significativas nos níveis de LH e de testosterona em animais alimentados com 7\% e 16\% de proteína bruta na dieta. ALTHEN et al. (1974) avaliaram 24 varrões, alimentados por um período de 1 ano, com dietas contendo níveis protéicos de 10, 15 e 20\%, os autores concluíram que o nível protéico da dieta influiu significativamente nos níveis dos hormônios luteinizante (LH) e folículo estimulante (FSH) encontrados, e que uma dieta contendo um nível de 10\% de proteína é capaz de proporcionar um desenvolvimento normal dos testículos, túbulos seminíferos e demais órgãos reprodutivos de varrões ao atingirem os 230 dias de idade, sendo que concentração de FSH no extrato de hipófise foi maior nos animais que receberam o nível mais alto de proteína na dieta, demonstrando que a adequada nutrição na fase de crescimento é necessária para melhoria da atividade reprodutiva de suínos machos inteiros.

A nutrição dos machos reprodutores pode influenciar a quantidade de sêmen (número de espermatozóides e volume do ejaculado), especialmente nos animais jovens e sob condições desfavoráveis de ambiente, já que é bem conhecida a depressão da alta temperatura sobre a produção de sêmen (HUGONIN, 2001). Segundo o mesmo autor o impacto da nutrição com a variação da ingestão de energia e proteína mostra efeitos expressivos na libido. Estudos conduzidos por CRESWELL et al. (1975) demonstraram que suínos alimentados com dietas de 13 a $11 \%$ de proteína bruta obtiveram baixo desenvolvimento, no entanto, isso foi melhorado quando se adicionou lisina à ração. No experimento realizado por KEMP et al. (1988), com o uso de rações comerciais utilizadas para fêmeas gestantes, contendo níveis de $14,47 \%$ de proteína bruta (PB), e fornecidas a 97 varrões da raça Yorkshire, 
PINTO, L.C.F. et al. Efeito dos níveis de proteína bruta da ração no comportamento e maturidade sexual de suínos machos. PUBVET, Londrina, V. 5, N. 20, Ed. 167, Art. 1128, 2011.

demonstraram que este é um nível adequado de proteína, promovendo boa exibição da libido e manutenção de bom número e boa qualidade de células espermáticas por ejaculado. LOUIS et al. (1994) avaliaram 20 varrões mestiços Landrace $\mathrm{x}$ Large White, com 1 ano de idade, consumindo níveis de 146 g (grupo 1) e 324 g (grupo 2) de proteína bruta na dieta por dia, observaram que, após 16 semanas de consumo da ração, os animais do grupo 1 necessitaram de $94 \%$ a mais de tempo para a obtenção do ejaculado, após o salto sobre o manequim, sugerindo uma diminuição na libido.

PRADO (2002) relatou que a espermatogênese em suínos parece ser afetada somente pela nutrição em condições de subnutrição severa e que quando a dieta oferecida aos animais for menor que a exigência nutricional adequada, a maturidade sexual também pode ser atrasada. LOUIS et al. (1994) observaram que em suínos recebendo menos de $50 \%$ da exigência recomendada em proteína, apresentaram decréscimo da libido, o que pode ter ocorrido em virtude da diminuição da concentração de estradiol 17circulante.

DONZELE et al. (1994) avaliando indiretamente o efeito de diferentes níveis de proteína bruta (12\% a 18\%) sobre a espermatogênese, pela análise histológica do testículo, obtiveram melhora no rendimento da espermatogênese até o nível de $16,21 \%$ de PB na ração, ainda segundo o mesmo estudo, os autores concluíram que o aumento do nível de PB na ração influenciou positivamente a espermatogênese. Para que haja avaliação precisa da exigência dos futuros reprodutores, é necessário avaliar dados ponderais como ganho de peso e conversão alimentar e, também, características como libido, biometria testicular e epididimária, exames macroscópicos e microscópicos do sêmen, além de análise histológica dos testículos e epidídimo (PRADO, 2002). Portanto, nota-se a importância de um correto desenvolvimento na formulação das dietas a serem oferecidas para reprodutores suínos VALENÇA (2007). 
PINTO, L.C.F. et al. Efeito dos níveis de proteína bruta da ração no comportamento e maturidade sexual de suínos machos. PUBVET, Londrina, V. 5, N. 20, Ed. 167, Art. 1128, 2011.

\section{MATERIAL E MÉTODOS}

O estudo foi realizado no Setor de Suinocultura do Instituto Federal Goiano - Campus Rio Verde, no período de novembro de 2008 a outubro de 2009, para o monitoramento da maturidade sexual de suínos não castrados alimentados com rações contendo diferentes níveis de proteína bruta (PB) formuladas pela empresa CEREAL Nutrição Animal desde a desmama, onde desde então, os animais começaram a se alimentar das rações experimentais. Os tratamentos foram constituídos em função do nível protéico das rações, sendo:

Tratamento 1 (T12\%) - 12\% de PB;

Tratamento 2 (T16\%) - 16\% de PB;

Tratamento 3 (T20\%) - 20\% de PB.

Foram utilizados 11 animais de linhagens comerciais Large White $\mathrm{x}$ Pietrain (com predominância da raça Large White) separados de três leitegadas. Os animais foram selecionados aleatoriamente entre os tratamentos no dia do desmame, alojados em baias com piso de concreto, bebedouros tipo concha e cochos fixos de cimento, onde recebiam ração ad libitum. Para avaliação do comportamento sexual e adaptação dos leitões, a partir de 151 dias de idade os animais eram colocados em contato com o manequim para colheita de sêmen uma vez por semana, por um período de 15 minutos. Para estimular os leitões colocava-se sobre o manequim urina de porca em cio ou sêmen de varrão.

Na Tabela 1 são apresentados os ingredientes das rações experimentais. 
PINTO, L.C.F. et al. Efeito dos níveis de proteína bruta da ração no comportamento e maturidade sexual de suínos machos. PUBVET, Londrina, V. 5, N. 20, Ed. 167, Art. 1128, 2011.

TABELA 1 - Ingredientes das rações de suínos machos não castrados.

\begin{tabular}{lcccc}
\hline \multicolumn{1}{c}{ Ingredientes } & Unidade & $\mathbf{T 1 2} \%$ & $\mathbf{T 1 6 \%}$ & $\mathbf{T 2 0} \%$ \\
\hline Milho moído & $\%$ & 68,20 & 50,47 & 37,38 \\
Sorgo moído & $\%$ & 15,00 & 15,00 & 13,00 \\
Farelo de soja 45\% & $\%$ & 7,10 & 19,20 & 33,00 \\
Farinha de carne e ossos & $\%$ & 3,50 & 3,50 & 3,50 \\
Calcário calcítico & $\%$ & 3,30 & 3,00 & 3,200 \\
Açúcar & $\%$ & 1,00 & 4,00 & 4,00 \\
Fosfato bicalcico & $\%$ & 0,78 & 0,71 & 0,80 \\
Sal comum & $\%$ & 0,50 & 0,50 & 0,50 \\
Premix mineral e vitamínico. & $\%$ & 0,40 & 0,40 & 0,40 \\
Promotor de crescimento & $\%$ & 0,10 & 0,10 & 0,10 \\
Lisina em pó & $\%$ & 0,10 & 0,10 & 0,10 \\
BHT (antioxidante) & $\%$ & 0,02 & 0,02 & 0,02 \\
Óleo degomado & $\%$ & - & 3,00 & 4,00 \\
\hline \multicolumn{1}{c}{ Total } & & $\mathbf{1 0 0 , 0 0}$ & $\mathbf{1 0 0 , 0 0}$ & $\mathbf{1 0 0 , 0 0}$ \\
\hline
\end{tabular}

Na Tabela 2 estão expostos os valores de atendimento das exigências nutricionais nos diferentes tratamentos. 
PINTO, L.C.F. et al. Efeito dos níveis de proteína bruta da ração no comportamento e maturidade sexual de suínos machos. PUBVET, Londrina, V. 5, N. 20, Ed. 167, Art. 1128, 2011.

TABELA 2 - Propriedades nutricionais das rações de suínos não castrados.

\begin{tabular}{lcccc}
\hline \multicolumn{1}{c}{ Nutriente } & Unidade & T12\% & T16\% & T20\% \\
\hline Proteína bruta & $\%$ & 12,00 & 16,00 & 20,00 \\
Fibra bruta & $\%$ & 2,10 & 2,30 & 2,20 \\
Energia metabolizável Suínos & Mcal/kg & 2,78 & 2,72 & 2,70 \\
Gordura & $\%$ & 3,50 & 3,60 & 4,00 \\
Matéria mineral & $\%$ & 2,90 & 3,80 & 3,50 \\
Cálcio & $\%$ & 1,60 & 1,58 & 1,70 \\
Fósforo total & $\%$ & 0,70 & 0,62 & 0,65 \\
Ferro & $\mathrm{mg} / \mathrm{kg}$ & 51,00 & 51,00 & 51,00 \\
Cobre & $\mathrm{mg} / \mathrm{kg}$ & 21,00 & 21,00 & 21,00 \\
Iodo & $\mathrm{mg} / \mathrm{kg}$ & 1,40 & 1,40 & 1,40 \\
Manganês & $\mathrm{mg} / \mathrm{kg}$ & 0,06 & 0,06 & 0,06 \\
Zinco & $\mathrm{mg} / \mathrm{kg}$ & 105,00 & 105,00 & 105,00 \\
Sódio & $\mathrm{g} / \mathrm{kg}$ & 2,50 & 2,50 & 2,50 \\
Vit. A & $\mathrm{UI} / \mathrm{kg}$ & 3000,00 & 3000,00 & 3000,00 \\
Vit. D3 & $\mathrm{UI} / \mathrm{kg}$ & 1800,00 & 1800,00 & 1800,00 \\
Vit. E & $\mathrm{mg} / \mathrm{kg}$ & 30,00 & 30,00 & 30,00 \\
Vit. K3 & $\mathrm{mg} / \mathrm{kg}$ & 6,00 & 6,00 & 6,00 \\
Vit. B12 & $\mathrm{mg} / \mathrm{kg}$ & 20,00 & 20,00 & 20,00 \\
\hline & & & & \\
\hline
\end{tabular}

O manequim era constituído de estrutura metálica revestido por uma manta de borracha para maior conforto dos animais e evitar incisões na região abdominal e prepúcio. Desde o início da fase de adaptação, tentava-se realizar a colheita de sêmen, no momento que os leitões montavam no manequim com o pênis exposto. Avaliou-se o comportamento macho dos leitões durante 15 minutos, considerando-se uma escala de zero a cinco, para a quantidade de vezes que realizavam a exposição do pênis e número de vezes que montavam 
PINTO, L.C.F. et al. Efeito dos níveis de proteína bruta da ração no comportamento e maturidade sexual de suínos machos. PUBVET, Londrina, V. 5, N. 20, Ed. 167, Art. 1128, 2011.

no manequim.

Antes de serem levados ao manequim para realização das colheitas de sêmen os leitões passavam por uma higienização da região do prepúcio com papel toalha. A colheita de sêmen era realizada com luvas descartáveis de vinil com redutor alérgico, segundo o método da mão enluvada, utilizando-se Becker de plástico $(500 \mathrm{~mL})$ pré aquecido a $37^{\circ} \mathrm{C}$ para colheita de sêmen e filtro para separação da fração gelatinosa. Quando os leitões ejaculavam, após a colheita, o sêmen era encaminhado ao laboratório da Estação Experimental de Zootecnia, onde foram analisados os seguintes parâmetros: concentração (CONC - milhões $/ \mathrm{mL}$ ), motilidade total (MT - \%), motilidade progressiva (MP $\%$ ), vigor ( $\mathrm{V}$ - 0 a 5) e alterações na morfologia espermática (AM).

A concentração era avaliada através de espermiodensímetro e a MT, MP e vigor foram avaliados através de microscópio óptico, com uma gota de sêmen entre lâmina e lamínula pré - aquecidas. A morfologia espermática foi avaliada através de esfregaço de sêmen em lâmina corada com rosa bengala. As colheitas permaneceram até os varrões apresentarem uma boa qualidade de sêmen por cinco colheitas consecutivas, com mais de $70 \%$ de motilidade total e com no máximo $20 \%$ de espermatozóides morfologicamente anormais. Neste momento os varrões foram considerados sexualmente maduros, aptos a reprodução.

Para a análise estatística, utilizou-se um delineamento inteiramente casualizado mediante a aplicação do teste Tukey. O nível de significância considerado foi de $5 \%$, sendo o programa utilizado para as análises estatísticas o software SAS versão 9.0 (2002).

\section{RESULTADOS E DISCUSSÃO}

Na Tabela 3 são apresentados os resultados médios do comportamento sexual de leitões, recebendo ração contendo níveis crescentes de proteína bruta, desde a desmama até atingirem a maturidade sexual. 
PINTO, L.C.F. et al. Efeito dos níveis de proteína bruta da ração no comportamento e maturidade sexual de suínos machos. PUBVET, Londrina, V. 5, N. 20, Ed. 167, Art. 1128, 2011.

TABELA 3 - Resultados médios do comportamento sexual de suínos não castrados, recebendo ração contendo diferentes níveis de proteína bruta. No período de 15 minutos.

\begin{tabular}{lccc}
\hline \multirow{1}{*}{\multicolumn{1}{c}{ Parâmetros }} & \multicolumn{3}{c}{ Tratamentos } \\
\cline { 2 - 4 } & $\mathbf{T 1 2 \%}$ & $\mathbf{T 1 6 \%}$ & $\mathbf{T 2 0 \%}$ \\
\hline Comportamento macho & $2,70 \mathrm{ab}$ & $2,97 \mathrm{a}$ & $2,11 \mathrm{~b}$ \\
Saltos sobre o manequim & $1,29 \mathrm{a}$ & $1,40 \mathrm{a}$ & $1,22 \mathrm{a}$ \\
Exposição do pênis & $0,86 \mathrm{a}$ & $1,03 \mathrm{a}$ & $0,76 \mathrm{a}$
\end{tabular}

*Médias seguidas de letras minúsculas distintas na mesma linha, diferem significativamente entre si pelo teste Tukey $(P<0,05)$.

Os animais alimentados com rações contendo $16 \%$ de PB apresentaram os melhores resultados para o comportamento macho, enquanto os animais que receberam ração com $20 \%$ de proteína bruta os valores obtidos foram menores. Este parâmetro era avaliado pelo comportamento do macho perante a fêmea e/ou manequim em um período de 15 minutos, que consistia no ato de grunhir, salivar, esfregar-se e focinhar. Comportamentos esses, também descritos por SILVA et al. (2008). FERREIRA et al., (2005) conclui que capacidade de monta parece não ser um fator limitante para o início da vida reprodutiva dos machos Landrace e Large White dentro do período avaliado.

Os resultados médios de saltos sobre o manequim não diferiram entre si, houve uma variação de 1,22 a 1,40 montas. KEMP et al. (1988), não encontraram efeito da alimentação sobre a libido de suínos. No entanto HUGONIN (2001) verificou impacto da nutrição com a variação da ingestão de energia e proteína, mostrando efeitos expressivos na libido. Este parâmetro era avaliado pelo número de montas exercido pelo varrão sobre a fêmea ou manequim durante o período de 15 minutos, após esse período caso o animal subisse no manequim, não se considerava como monta. Esse comportamento dos leitões conforme VALENÇA et al. (2007) é observado logo os 30 dias de 
PINTO, L.C.F. et al. Efeito dos níveis de proteína bruta da ração no comportamento e maturidade sexual de suínos machos. PUBVET, Londrina, V. 5, N. 20, Ed. 167, Art. 1128, 2011.

idade, com o ato de realizar saltos sobre outro animal, sendo mais observado nos machos quando comparados com as fêmeas. Ainda segundo o mesmo autor, a libido é uma característica geralmente estimada através da contagem do número de saltos realizados pelo varrão sobre um manequim ou diretamente sobre uma fêmea em estro, registrando-se o sucesso no procedimento em um período de tempo pré-determinado. LOUIS et al. (1994), em experimento utilizando 20 varrões mestiços LD x LW com 1 ano de idade, consumindo níveis de $146 \mathrm{~g}$ (grupo 1) e $324 \mathrm{~g}$ (grupo 2) de proteína bruta na dieta, observaram que após 16 semanas de consumo da ração, os animais do grupo 1 necessitaram de 94\% mais de tempo para a obtenção do ejaculado, após o salto sobre o manequim, sugerindo portanto, uma diminuição na libido.

Não foi observada diferença significativa para o parâmetro exposição de pênis no período de 15 minutos. Este parâmetro é de grande importância, visto que, a não exposição do pênis pode ser relacionada a alguma anormalidade que possa estar acometendo o animal durante a cópula como, lesões, aderência, e má formação. Este parâmetro é citado por GAGGINI et al., (2008) como uma das avaliações no exame do sistema reprodutor suíno. O mesmo autor relatou ainda que as fases da cópula devam ser avaliadas separadamente (excitação, aproximação, ereção, monta, introdução, propulsão e ejaculação, descida e fim do ato de monta).

$\mathrm{Na}$ Tabela 4 estão expostas as médias do percentual de motilidade total (\%), motilidade progressiva (\%), espermatozóides com alterações na morfologia espermática (\%), vigor (0-5), concentração espermática (x 10\% $/ \mathrm{ml})$ e idade com que os animais atingiram a maturidade sexual. 
PINTO, L.C.F. et al. Efeito dos níveis de proteína bruta da ração no comportamento e maturidade sexual de suínos machos. PUBVET, Londrina, V. 5, N. 20, Ed. 167, Art. 1128, 2011.

TABELA 4 - Resultados médios do percentual de motilidade total (\%), motilidade progressiva (\%), espermatozóides com alterações morfológicas (\%), vigor (0-5), concentração espermática (x 106/mL) e idade com que os animais atingiram a maturidade sexual de varrões, desde a desmama até atingirem a maturidade sexual.

\begin{tabular}{|c|c|c|c|}
\hline \multirow{2}{*}{ Parâmetros } & \multicolumn{3}{|c|}{ Tratamentos } \\
\hline & T12\% & T16\% & T20\% \\
\hline Motilidade total (\%) & $86,54 a$ & $88,69 a$ & $84,61 a$ \\
\hline Motilidade progressiva (\%) & $80,09 a$ & $81,96 a$ & $78,46 a$ \\
\hline Vigor $(0-5)$ & $3,31 a$ & $3,37 a$ & $3,00 a$ \\
\hline Concentração $\left(x 10^{6} / \mathrm{mL}\right)$ & $576,27 a$ & $556,67 a$ & $566,10 a$ \\
\hline $\begin{array}{l}\text { Alterações na morfologia espermática } \\
(\%)\end{array}$ & $17,79 a$ & $23,37 a$ & $13,08 \mathrm{a}$ \\
\hline Idade da maturidade sexual (dias) & $340 a$ & $320 a$ & $282 b$ \\
\hline
\end{tabular}

$\mathrm{Na}$ apresentação da Tabela 4 foram considerados todos os ejaculados obtidos dos leitões, desde a fase de adaptação até os mesmos serem considerados sexualmente maduros.

Para a motilidade total e progressiva, os resultados encontrados neste experimento não apresentaram diferença ao nível de significância de 5\%, resultados estes, que se encontraram dentro do percentual mínimo aceitável de espermatozóides móveis, que de acordo com BORTOLLOZO et. al., (2005b) é de 70\%. Segundo COLENBRANDER et al. (1993), os ejaculados apresentando percentuais de células móveis abaixo de $70 \%$ devem ser descartados. A motilidade é um atributo importante para o deslocamento espermático no trato reprodutivo e para a penetração no oócito BERNARDI (2008). FLOWERS (1997) relatou que a fertilidade é comprometida, caso a motilidade esteja abaixo de 
PINTO, L.C.F. et al. Efeito dos níveis de proteína bruta da ração no comportamento e maturidade sexual de suínos machos. PUBVET, Londrina, V. 5, N. 20, Ed. 167, Art. 1128, 2011.

$60 \%$. Em estudos realizados pelo mesmo autor, foi demonstrado que o emprego de doses contendo $66,2 \%$ a $94,7 \%$ de motilidade, não sofreram influência na taxa de parto e no tamanho da leitegada.

Semelhante aos parâmetros encontrados para motilidade no presente estudo, KEMP et al., (1988) fornecendo dois tipos de dietas com níveis de $14,5 \%$ e $22,2 \%$ de proteína bruta, concluíram que as variações protéicas não interferiram na qualidade do ejaculado, seja para o número de células espermáticas por ejaculado, seja para motilidade. LOUIS et al. (1994), não observaram alterações no número de espermatozóides defeituosos e na motilidade de ejaculados obtidos de varrões que consumiram níveis de $7 \%$ e 16\% de proteína bruta na dieta. Já OLIVEIRA et al., (2006) utilizando rações isoprotéicas contendo $13,5 \%$ de proteína bruta, observaram média de motilidade de $80,71 \%$.

Os resultados do parâmetro vigor não diferiram significativamente entre si, sendo os valores encontrados no presente estudo menores do que os encontrados no experimento realizado por OLIVEIRA et al. (2006), que utilizando rações isoprotéicas contendo $13,5 \%$ de proteína bruta observaram média de 3,81. De acordo com BORTOLOZZO et al. (2005b), o vigor corresponde aos espermatozóides que se movimentam progressivamente, levando em consideração o tipo e a direção do movimento.

Os valores da concentração espermática não resultaram em diferença estatística entre os tratamentos, no entanto os resultados encontrados no presente estudo foram superiores aos obtidos por FERREIRA et al. (2005), que avaliando o comportamento de monta e características seminais de suínos jovens LD e LW , observaram valores médios de $164,76 \times 10^{6}$ e $155,99 \times 10^{6}$ espermatozóides/mL, respectivamente.

Os valores das alterações na morfologia espermática encontradas neste estudo não diferiram estatisticamente entre si. Resultados esses também observados por YEN \& YU (1985) que não encontraram efeitos significativos sobre a porcentagem de espermatozóides defeituosos através da elevação dos 
PINTO, L.C.F. et al. Efeito dos níveis de proteína bruta da ração no comportamento e maturidade sexual de suínos machos. PUBVET, Londrina, V. 5, N. 20, Ed. 167, Art. 1128, 2011.

níveis protéicos na dieta. Os valores de espermatozóides com alterações morfológicas do T12\% e T20\% encontraram-se dentro do recomendado pela (CBRA, 1998) que relata que as alterações morfológicas totais deverão ser inferiores a $20 \%$. Já o T16\% resultou em valores superiores aos recomendados para alterações na morfologia espermática, o que pode ocasionar em problemas na capacidade fecundante do sêmen, bem como diminuição da taxa de concepção. FEITSMA et al., (2006) observaram que em ejaculados com média de $15,5 \%$ de defeitos, foi calculada uma diminuição de $0,2 \%$ na taxa de não retorno ao estro, de $0,5 \%$ na taxa de parto, e de 0,08 leitões nascidos para um aumento de $20 \%$ a $30 \%$ no percentual de anormalidades. XU et al. (1998) avaliando inseminações efetuadas com doses de dois bilhões de espermatozóides, observaram que o percentual de espermatozóides normais foi responsável por 59\% na variação do tamanho da leitegada.

Nas condições desse estudo o parâmetro maturidade sexual apresentou diferença significativa entre os suínos que receberam ração contendo $20 \%$ e os animais que receberam rações com $12 \%$ e $16 \%$ de PB. Os animais dos tratamentos $\mathrm{T} 12 \%$ e $\mathrm{T} 16 \%$ atingiram a maturidade sexual aos 340 e 320 dias respectivamente, enquanto os animais que receberam ração com $20 \%$ de PB a maturidade sexual ocorreu aos 282 dias. Esse resultado foi ligeiramente superior ao descrito por MURGAS et al. (2001), que observaram a idade de 200 dias, ou ao redor dos sete meses de idade para a puberdade de suínos. Segundo FERRELL (1991) animais jovens são mais sensíveis a problemas relacionados com má nutrição do que aqueles já adultos e, em algumas circunstâncias, podem sofrer danos que podem repercutir em toda sua vida reprodutiva. PRADO (2002) relatou que a espermatogênese em suínos parece ser afetada somente em condições de subnutrição severa e que quando a dieta oferecida aos animais for menor que a exigência nutricional adequada, a maturidade sexual também pode ser atrasada. Segundo LEATHEM (1970), problemas de subnutrição em animais na fase pré-púbere, resultaram em retardo no desenvolvimento sexual, atraso no alcance da puberdade, demora 
PINTO, L.C.F. et al. Efeito dos níveis de proteína bruta da ração no comportamento e maturidade sexual de suínos machos. PUBVET, Londrina, V. 5, N. 20, Ed. 167, Art. 1128, 2011.

no desenvolvimento da genitália externa e conseqüente supressão da espermatogênese.

De acordo com os parâmetros avaliados neste estudo, nota-se que não se faz necessário o uso de rações com altos teores de PB para machos destinados à serem futuros reprodutores de uma granja suinícola.

A partir do estudo da avaliação dos efeitos dos níveis de proteína bruta na ração sobre o comportamento e maturidade sexual de suínos na Estação Experimental de Zootecnia, foram selecionados alguns reprodutores que participaram do experimento, os quais estão servindo como reprodutores da granja do Instituto Federal Goiano - Campus Rio Verde na função de doadores de sêmen para a IA.

\section{CONCLUSÕES}

Os suínos machos não castrados alimentados com dieta à base de $16 \%$ de PB apresentaram melhor comportamento macho. O teor de proteína bruta não influenciou o número de montas e o número de vezes que o animal expos o pênis.

Não houve diferença na qualidade do sêmen de varrões arraçoados com diferentes níveis de proteína bruta $(12 \%, 16 \%$ e $20 \%)$ desde a desmama até atingirem a maturidade sexual.

Os animais que receberam ração com $20 \%$ de PB atingiram a maturidade sexual mais rápido do que os animais arraçoados com 12 e 16\% de PB.

\section{REFERÊNCIAS BIBLIOGRÁFICAS}

ALTHEN T. G.; GERRITS R. J.; YOUNG E. P. Pituitary gonadotropins in boars as affected by dietary protein and age. Journal of Animal Science. v. 39, p. $601-605,1974$.

ASSOCIAÇÃO BRASILEIRA DA INDÚSTRIA PRODUTORA E EXPORTADORA DE CARNE SUÍNA E EMPRESA BRASILEIRA DE PESQUISA AGROPECUÁRIA. (ABIPECS/EMBRAPA). 2010.

Levantamento Sistemático da Produção e Abate de Suínos (LSPS). Disponível em: <http://www.abipecs.org.br>. Acesso em: 22 abr. 2010. 
ASSOCIAÇÃO BRASILEIRA DA INDÚSTRIA PRODUTORA E EXPORTADORA DE CARNE SUÍNA. (ABIPECS, SIPS, SINDICATOS RS E PR, EMBRAPA). Estimativas - matrizes industriais alojadas no Brasil - 2004 A 2010. Disponível em: <http://www.abipecs.org.br>. Acesso em: 22 abr. 2010.

ASSOCIAÇÃO BRASILEIRA DA INDÚSTRIA PRODUTORA E EXPORTADORA DE CARNE SUÍNA. Carne suína brasileira em 2008. Disponível em: <http://www.abipecs.org.br>. Acesso em: 22 abr. 2010.

BERNARDI M. L. Tecnologias aplicadas no exame do ejaculado suíno para a produção de doses de sêmen de alta qualidade. Acta Scientiae Veterinariae. Supl 1, p. 5 - 16, 2008.

BORTOLOZZO, F. P.; WENTZ I.; DALLANORA D. Situação atual da inseminação artificial em suínos. Acta Scientiae Veterinariae, v. 33, p. 17 - 32, 2005a.

BORTOLOZZO, F. P.; WENTZ, I.; BENNEMAMM, P. E.; BERNARDI, M. L.; WOLLMANN, E. B.; FERREIRA, F. M.; BORCHARDT N. G.; Suinocultura em ação. Inseminação artificial na suinocultura tecnificado, cap. 7, p. $69-87$, Porto Alegre, 2005b.

BROWN B. W. A revew of nutritional influences on reproduction in boars, bulls and rams. Reproduction Nutrition Development, v. 34, p. 89 - 114, 1994.

COLEGIO BRASILEIRO DE REPRODUÇÃO ANIMAL. Manual para exame andrológico e avaliação do sêmen animal ( $2^{a}$ ed), p. 49, Belo Horizonte, CBRA, 1998.

COLENBRANDER B.; KEMP B. Factors infliencing semen quality in pigs. Journal of Reproduction and Fertility. Suppl., v. 40, p. $105-115,1990$.

COLENBRANDER, B.; FEISTMA, H.; GROOTEN, H. J. Optmizing sêmen production for artificial insemination in swine. Journal of reproduction and fertility, Suppl 48, p. $207-215,1993$.

CRESWELL, D. C.; WALLACE G. E.; COMBS A. Z.; et al. Lysine and tryptophan in diets for boards and barrows, Journal of Animal Science, v. 40, p. 167 - 168, 1975.

DONZELE, J. L.; PAULA T. A. R.; FREITAS T. F. F.; et al. Níveis de proteina bruta para suínos machos inteiros, dos 60 aos $100 \mathrm{~kg}$ de peso vivo. Revista da Sociedade Brasileira de Zootecnia. v. 23, n. 4, p. $3-13,1994$.

FEITSMA H.; BERGSMA R.; DUCRO-STEVERINK D. W. The effect of morphological abnormal cells on sow fertility. In: PROCEEDINGS OF THE 19TH INTERNATIONAL PIG VETERINARY SOCIETY CONGRESS (Copenhagen, Denmark), Abstract... 2006. p. 545.

FERREIRA F. M.; WENTZ I.; SCHEID I. R.; AFONSO S. B.; GUIDONI A. L.; BORTOLOZZO F. P., Comportamento de monta e características seminais de suínos jovens landrace e large White. Ciencia Rural. v. 35, p. 131 - 137, 2005.

FERREIRA, F. M. Comportamento sexual e características espermáticas em suínos jovens. In: CONGRESSO BRASILEIRO DE REPRODUÇÃO ANIMAL, Belo Horizonte. Anais... Belo Horizonte: 1995. p. $26-34$.

FERRELL, C. L. Nutritional influences on reproduction. In: CUPPS PT (ED.). REPRODUCTION IN DOMESTIC ANIMALS, 4TH.ED. New York: Academic Press Inc, p. 577 - 603, 1991. 
FLOWERS B. Reproductive physiology of the boars. In: SWINE REPRODUCTION SYMPOSIUM., 1996, HASTINGS, NE. PROCEEDINGS HASTINGS, NE: American College of Theriogenologists,. p. $1-6,1996$.

FLOWERS W. L. Management of boars for efficient semen production. Journal of Reproduction and Fertililty. Suppl 52, p. $67-78,1997$.

FLOWERS W. L. Boar fertility and artificial insemination. In: IPVS CONGRESS, 15, 1998, BIRMINGHAM.PROCEEDING. BIRMINGHAM: NOTTINGHAM UNIVERSITY PRESS. 1998, p. 45 52.

FURTADO C. S. D.; MELLAGI A. P. G.; VARGAS A. J.; BORTOLOZZO F. P.; WENTZ I.; BERNARDI M. L. Aspectos Relevantes na Avaliação da Morfologia Espermática do Suíno. In: I SIMPÓSIO UFRGS SOBRE PRODUÇÃO, REPRODUÇÃO E SANIDADE SUÍNA. Porto Alegre, RS, 2006.

GADEA J. Sperm factors related to in vitro and in vivo porcine fertility. Theriogenology. suppl 63 , p. $43-444,2005$.

GAGGINI T. S.; MURGAS L. D. S.; ZANGERONIMO M. G. Seleção de reprodutores suínos. Boletim Técnico - n. ${ }^{\circ}$ 81, p. 1 - 14, Lavras/MG, 2008.

GONÇALVES R. G.; PALMEIRA E. M. "Suinocultura Brasileira" en Observatorio de la Economía Latinoamericana, Número 71, 2006.

HUGONIN, L. Avanços tecnológicos na nutrição de Machos reprodutores suínos. In: 90 SEMINÁRIO NACIONAL DE DESENVOLVIMENTO DA SUINOCULTURA 25 A 27 DE ABRIL. Gramado, RS. 2001.

instituto BRASILEIRO DE GeOgrafia e eStatisticA. IBge. Produção Animal no $\mathbf{1}^{\circ}$ Trimestre de 2009. Disponível em:

<http://www.ibge.gov.br/home/estatistica/indicadores/agropecuaria/producaoagropecuaria.> Acesso em: 30 mai. 2010.

KEMP B.; DEN HARTOG L. A.; GROOTEN H. J. G. The efect of feeding level on semen quantity and quality of breeding boars. Animal Reproduction Science, v. 20, p. 245 - 254, 1989.

KEMP B.; GROOTEN H. J. G.; DEN HARTOG L. A.; LUITING P.; VERSTEGEN M. W. A. The effect of a high protein intake on sperm production in boars at two semen collection frequencies.

Animal Reproduction Science, v. 17, p. 103 - 113, 1988.

KEMP B.; VERSTEGEN M. W. A. Nutrition and sperm production. Reprod Dom Anim Suppl, n.1, p.287-296, 1991. Leathem JH. Nutrition. In: JOHNSON AD, GOMES WR, VANDEMARK III, NL (ED.). THE TESTIS. New York: Academic Press, p. $169-205,1970$.

LEATHEM J. H., Nutrition. In: JOHNSON A.D., GOMES W.R., VANDEMARK III, N.L., (ED.). THE TESTIS. New York: Academic Press, p. 169 - 205, 1970.

LOUIS G. F.; LEWIS A. J.; WELDON W. C.; MILLER P. S.; KITTOG; STROUP W. W. The effect of protein intake on boar libido, semen characteristics and plasma hormone concentrations.

Journal of Animal Science, v. 72, p. 2038 - 2050, 1994.

MARTINEZ R. H.; ERIKSSON B. Evaluación del semen de verraco y su relación con fertlidad. In: SIMPÓSIO INTERNACIONAL MINITUB, FLORES DA CUNHA-RS, 2000. p. 13 - 33. 
MORROW, D. A. Current therapy in theriogenology: diagnosis, treatment and prevention of reproductive diseases in small and large animals. New York: Saunders. p. 1143, 1986.

MURGAS, L. D. S.; FIALHO E. T.; OLIVEIRA A. I. G.; LIMA J. A. F. Desempenho reprodutivo de varrões híbridos alimentados com rações suplementadas com óleo de soja como fonte de ácidos graxos. Ciência e Agrotecnologia, Lavras, v. 25, p. 1423 - 1434, 2001.

NEELY, J. D. Sexual behaviour and testicular development in purebred and crossbred boars. Dissertation Abstracts International, v. 43, n.6, p. 1673B, 1982.

OBERLENDER G.; MURGAS L. D. S.; LIMA D.; GAGGINI T. S.; ZANGERONIMO M. G.; ALVARENGA A. L. N.; E SILVA D. M. Alterações endócrinas em reprodutores suínos de alto desempenho. Ciência Animal Brasileira, Goiânia. v. 11, p. 245 - 250, 2010.

OBERLENDER G.; MURGAS L. D. S.; MESQUITA S. P. Inseminação artificial em suínos. Boletim Técnico - n. 079 - p. 1 - 16. Lavras/MG, 2008.

OLIVEIRA S. L.; FIALHO E. T.; MURGAS L. D. S.; FREITAS J. A.; FREITAS R. T. F.; ZANGERONIMO M. G. Efeito da inclusão de diferentes tipos de óleo na dieta de varrões sobre a qualidade do sêmen "in natura". Ciência e Agrotecnologia, Lavras, v. 30. n.6, Lavras Nov./Dec., 2006.

PLATT B.S.; STEWART R.J.C. Experimental protein-calorie deficiency: histopathological changes in the endocrine glands of pigs. Journal of Endocrinology, v. 38, p. $121-143$, 1967.

PRADO A. E. Lisina e energia digestível em rações para suínos machos em fase puberal. Dissertação (Mestrado), Viçosa, MG, 2002.

ROPPA L. Tendências da suinocultura mundial e as oportunidades brasileiras. Anuário da Pecuária Brasileira. São Paulo, p. 281 - 284, 2002.

ROSTAGNO, H. S. Tabelas brasileiras para aves e suínos, composição de alimentos e exigências nutricionais. Viçosa. p. 141, 2000.

SAS., 2002. SAS Systems for Windows 9.0. SAS Institute Inc., Cary, NC, USA.

SCHEID, I. R.; AFONSO, S. B. Treinamento e manejo de machos suínos jovens e adultos. In: SIMPÓSIO INTERNACIONAL DE REPRODUÇÃO E INSEMINAÇÃO ARTIFICIAL EM SUÍNOS. 2000, Foz do Iguaçu. Anais... Piracicaba, 2000. p. 29 - 39.

SILVA D. M.; MURGAS L. D. S.; ALVARENGA A. L. N. Manejo da cobrição na suinocultura. Boletim Técnico. n. ${ }^{\circ}$ 80. p. 1 - 13. Lavras/MG, 2008.

SILVA F. C. O.; Donzele J. L.; Fonseca C. C.; Neves M. T. D.; Hannas M. I. Efeito dos níveis de energia digestível da ração sobre os parâmetros reprodutivos de suínos machos inteiros e fêmeas. Revista Brasileira de Zootecnia, v. 27, p. 965 - 973, 1998.

TARDIF S.; LAFOREST J. P.; CORMIER N.; BAILEY J. L. The importance of porcine sperm parameters on fertility in vivo. Theriogenology. p. $447-459,1999$.

VALENÇA R. M. B. Efeitos de diferentes níveis protéicos na dieta sobre o desenvolvimento de características produtivas e reprodutivas em reprodutores suínos dos 38 aos 210 dias de idade. 2004. Dissertação (Mestrado) - Universidade Federal Rural de Pernambuco, Recife, 2004. 
VALENÇA, R. M. B.; COSTA A. N.; JÚNIOR V. A. S.; REIS J.C.; MARTINS T. D. D.; Avanços na nutrição de varrões: efeitos sobre o desenvolvimento das características reprodutivas e qualidade do sêmen. Revista Brasileira de Reprodução Animal., Belo Horizonte, v. 31, n.1, p. 64 - 70, jan./mar. 2007. Disponível em: www.cbra.org.br.

WOLLMANN E. B.; BORTOLOZZO F. P.; WENTZ I.; BENNEMANN P. E.; BORCHARDT N. G.; FERREIRA F. M.; PERUZZO I. Differences in sperm output according to boar age in an AI centre. In: PROCEEDINGS OF THE 17TH IPVS CONGRESS (IOWA, USA). p. 488. Pub. 604, 2002.

XU X.; POMMIER S.; ARBOV T.; HUTCHINGS B.; SOTTO W.; FOXCROFT G. R. In vitro maturation and fertilization techniques for assessment of semen quality and boar fertility. Journal of Animal Science. 76: p. 3079 - 3089, 1998.

YEN H. T.; YU I. T.; Influence of digestible energy end protein feeding on semen characteristics of breeding boars. In: AAAP ANIMAL SCIENCE CONGRESS, 3RD, 1985, SEOUL. PROCEEDINGS: EFFICIENT ANIMAL PRODUCTION FOR ASIAN WELFARE. Seoul: AAAP, v. 2, p. $610-612$, 1985. 